This item was submitted to Loughborough's Research Repository by the author.

Items in Figshare are protected by copyright, with all rights reserved, unless otherwise indicated.

\title{
A compact and low-profile tunable loop antenna integrated with inductors
}

PLEASE CITE THE PUBLISHED VERSION

http://dx.doi.org/10.1109/LAWP.2008.2001028

PUBLISHER

(c) IEEE

VERSION

VoR (Version of Record)

LICENCE

CC BY-NC-ND 4.0

REPOSITORY RECORD

Lee, Dong Hyun, Alford Chauraya, J.C. Vardaxoglou, and Wee Sang Park. 2019. "A Compact and Low-profile Tunable Loop Antenna Integrated with Inductors”. figshare. https://hdl.handle.net/2134/9453. 
This item was submitted to Loughborough's Institutional Repository (https://dspace.lboro.ac.uk/) by the author and is made available under the following Creative Commons Licence conditions.

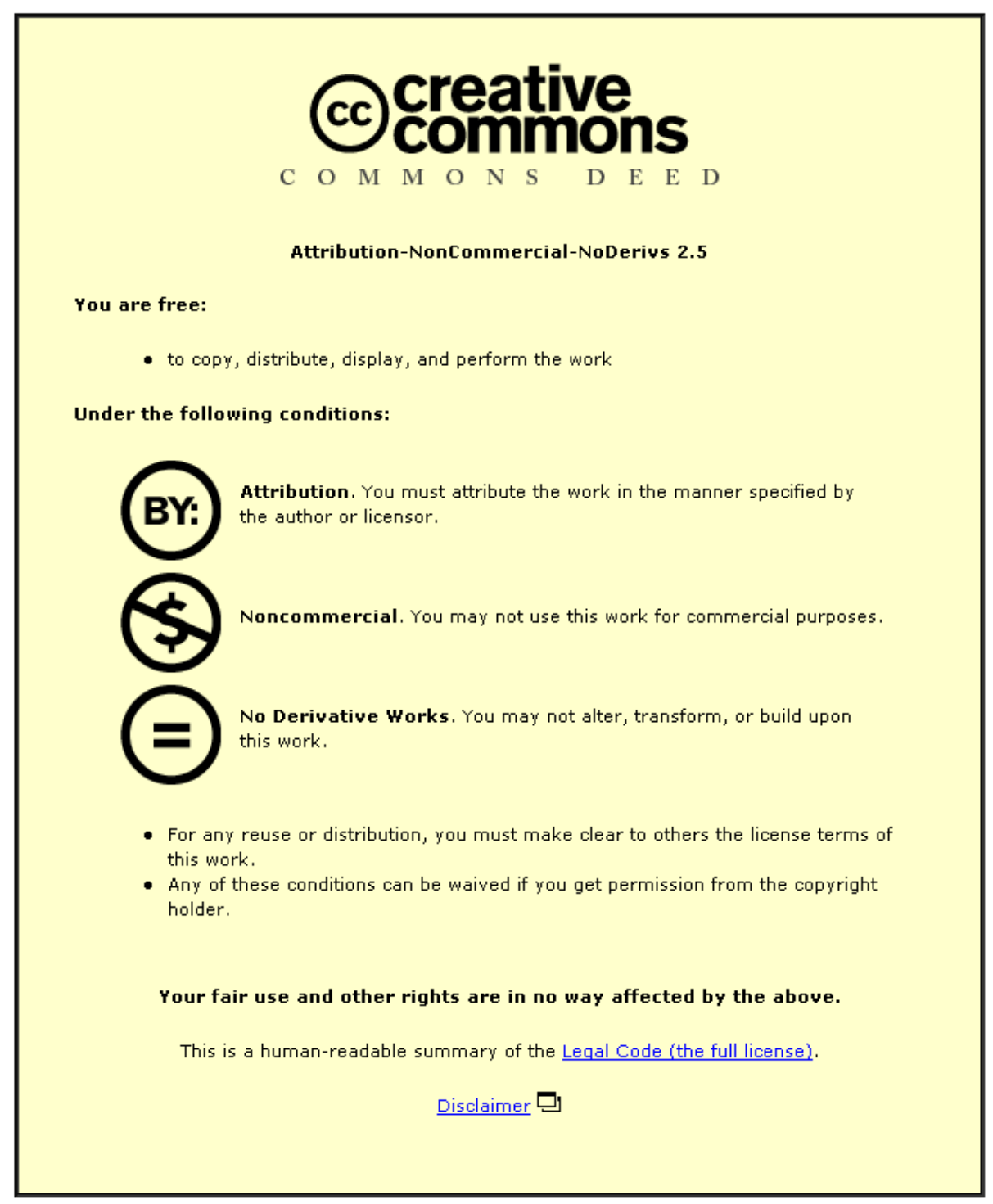

For the full text of this licence, please go to: http://creativecommons.org/licenses/by-nc-nd/2.5/ 


\title{
A Compact and Low-Profile Tunable Loop Antenna Integrated With Inductors
}

\author{
Dong Hyun Lee, Student Member, IEEE, Alford Chauraya, Member, IEEE, Yiannis Vardaxoglou, Member, IEEE, \\ and Wee Sang Park, Member, IEEE
}

\begin{abstract}
We present a frequency-tunable, compact loop antenna which consists of a transmission line on a ground plane, two shorting posts, and two inductors which are serially connected between the posts and the edge of the transmission line. By properly choosing the inductance of the inductors, the operating frequency of the antenna can be controlled without seriously sacrificing fractional bandwidth. To demonstrate the operating mechanism, the equivalent circuit of this antenna is included. The characteristics of the antenna with various inductors integrated are also investigated. Fabricated antennas show that the operating frequency can be shifted from $2.07 \mathrm{GHz}$ to $1.2 \mathrm{GHz}$ using off-the-shelf inductors. Using two 33-nH inductors achieves an antenna with an electrical size as small as $0.118 \lambda \times 0.013 \lambda \times 0.047 \lambda$. The validity of this antenna is demonstrated by experimental results.
\end{abstract}

Index Terms-Compact antenna, frequency tunable antenna, inductor, loop antenna.

\section{INTRODUCTION}

O IMPLE, small antennas with low profile and light weight are increasingly necessary as wireless communication devices become compact and the demand for low-frequency applications increases. Traditional techniques for miniaturizing antennas include lengthening the current path using shorting pins [1], slots [2], and meander lines [3], or lengthening the electrical dimension by employing a high dielectric material [4]. However, these techniques cause inescapable problems, such as narrowing bandwidth, increasing cross polarization level, and decreasing radiation efficiency. A circular-disk-loaded monopole antenna [5], which uses electromagnetic coupling and a folded conical helical antenna [6], has been reported to increase the bandwidth with compact size. However, these structures are complicated to fabricate.

In this letter, we propose a simple, lightweight, compact frequency-tunable loop antenna. This antenna structure consists of two rectangular substrates, two posts, and two inductors (Fig. 1). By altering the inductor values, the operating frequency can be

Manuscript received April 18, 2008; revised May 15, 2008. First published June 10, 2008; current version published December 30, 2008. This work was supported by the Korea Research Foundation Grant funded by the Korean Government (MOEHRD) (KRF-2006-612-D00069).

D. H. Lee and W. S. Park are with the Antenna Laboratory, Pohang University of Science and Technology, Pohang, 790-784, Korea (e-mail: donghyun@ postech.ac.kr).

A. Chauraya and Y. Vardaxoglou are with the Wireless Communications Research Group, and Centre of Mobile Communications Research, Department of Electronic and Electrical Engineering, Loughborough LE11 3TU, U.K.

Color versions of one or more of the figures in this paper are available online at http://ieeexplore.ieee.org.

Digital Object Identifier 10.1109/LAWP.2008.2001028

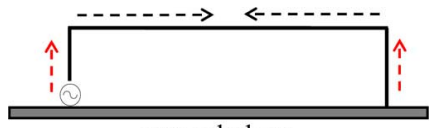

ground plane

(a)

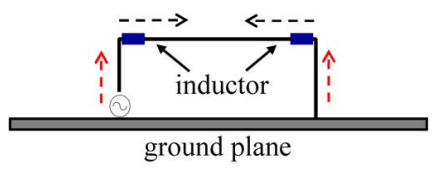

(b)

Fig. 1. Configuration of a loop antenna mounted on a ground plane and its current distribution. (a) Without an inductor. (b) With inductors.

shifted and the input impedance can be easily matched without degrading the fractional input impedance bandwidth. In Section II, we discuss an idea for miniaturizing a loop antenna by integrating inductors and introduce the configuration of the proposed antenna. The equivalent circuit model of the antenna is presented in Section III. In Section IV, we investigate the characteristics of the antenna with varying inductor pairs. In Section $\mathrm{V}$, we present the measured results to validate the simulated results, and we conclude this paper in Section VI.

\section{Consideration of Miniaturizing LoOP ANTENNA AND CONFIGURATION OF PROPOSED ANTENNA}

Fig. 1(a) shows a loop antenna mounted on a ground plane. The directions of current distributions on two vertical wires are the same, so both can contribute radiation. The current flows on the horizontal wire in opposite directions; these currents keep a resonance condition, but do not contribute to the radiation. Therefore, if we put inductors on the horizontal wire in order to give a phase delay with a small wire length, we can reduce the horizontal wire length. The induced phase delay from the integrated inductors keeps the resonance condition so that a current distribution of the conventional loop antenna is expected. We present this concept of a miniaturized antenna in Fig. 1(b). Note that the currents are highly concentrated on the edge of the upper horizontal wire, so we integrate the inductors at the edge of the horizontal wire to generate a large phase delay for a given inductance.

To implement this miniaturization idea, we have designed a 3-D loop antenna with two inductors as shown in Fig. 2. This antenna consists of an upper layer and a bottom layer, which are rectangular substrates of permittivity $\varepsilon_{r}$. The distance between layers is $h$. The bottom layer acts as a ground plane of length $g l(=$ line $l+10 \mathrm{~mm})$ and width $g w\left(=\right.$ line $\left.\_w+15 \mathrm{~mm}\right)$. A transmission line with length line_l and width line_w is placed 


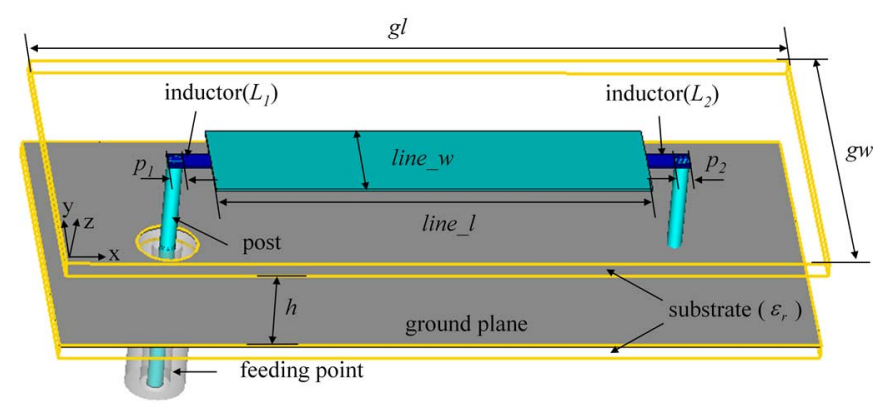

Fig. 2. Configurations of the proposed antenna.

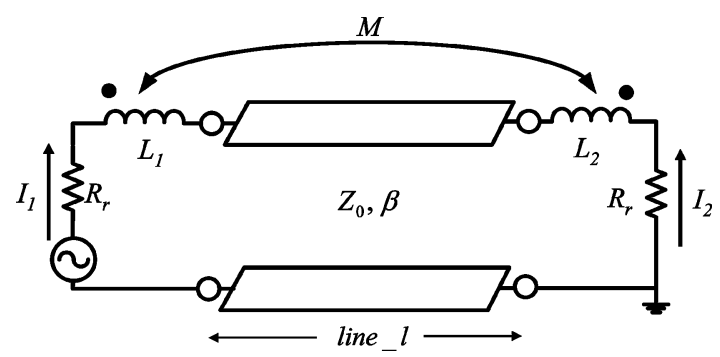

Fig. 3. Equivalent circuit model of the proposed antenna.

on the upper layer. At the end of the transmission line, two posts connect the transmission line through the ground plane. The diameters of the posts are $p_{1}$ and $p_{2}$. Two inductors $\left(L_{1}, L_{2}\right)$ are integrated between the posts and the transmission line.

\section{EQUivalENT CIRCUIT}

The derived equivalent circuit of the proposed antenna (Fig. 3) illustrates the operating mechanism of the antenna. The straight transmission line of length line_l and width line_w is simply modeled as a transmission line, with length line_l and width line_w with characteristic impedance $Z_{0}$ and propagation constant $\beta$. Since the two posts are the main radiation elements, the posts are modeled as a radiation resistance $R_{r}$ and $R_{r}$ makes the response of the circuit more broadband. Although several mutual inductive couplings occur between inductors on the equivalent circuit, only the mutual inductive coupling $(M)$ between $L_{1}$ and $L_{2}$ is considered for simplification.

To verify the equivalent circuit of the antenna, the results from a full-wave simulation and those from circuit simulation are compared in Table I. For full-wave analysis, CST's MWS full-wave simulator was used. For circuit analysis, Agilent's ADS was used. The parameters are set as $h=3 \mathrm{~mm}$, line $l=$ $20 \mathrm{~mm}$, line_ $w=1 \mathrm{~mm}, p_{1}=0.3 \mathrm{~mm}, p_{2}=0.5 \mathrm{~mm}$, and $\varepsilon_{r}=1$. Resonant frequency $\left(f_{0}\right)$, input impedance at resonant frequency $\left(Z_{r}\right)$, and input impedance bandwidth (BW) are summarized in Table I for several different values of $L_{1}$ and $L_{2}$.

The case of $L_{1}=0$ and $L_{2}=0$ (Table I) corresponds to the structure without the lumped inductors. The $R_{r}$ of the equivalent circuit can be determined by comparing the input impedance of the full-wave results when $L_{1}=L_{2}=0$. The input impedance of the full-wave analysis in this case is $6 \Omega$ (Table I). Therefore, due to the symmetry of the structure, we set each $R_{r}$ of the equivalent circuit to $3 \Omega$, and used this value of $R_{r}$ for different values of $L_{1}$ and $L_{2}$. Note that we only changed the physically
TABLE I

COMPARISON OF THE RESULTS FROM FULL-WAVE ANALYSIS AND THE RESULTS FROM CIRCUIT ANALYSIS $L_{1}, L_{2}$ : INDUCTANCE OF INTEGRATED INDUCTOR $(\mathrm{NH}), M$ : Mutual COUPLing (NH), $f_{0}$ : RESONANCE FREQUENCY $(\mathrm{GHz}), Z_{r}$ : INPUT IMPEDANCE AT RESONANCE FREQUENCY $(\Omega)$, BW: -10 dB INPUT IMPEDANCE BANDWIDTH (MHZ). N/A: NOT AVAILABLE

\begin{tabular}{cc|ccc|cccc} 
& & \multicolumn{3}{|c|}{ Full-wave analysis } & \multicolumn{4}{c}{ Circuit analysis } \\
\hline$L_{1}$ & $L_{2}$ & $f_{0}$ & $Z_{r}$ & $\mathrm{BW}$ & $M$ & $f_{0}$ & $Z_{r}$ & $\mathrm{BW}$ \\
\hline 0 & 0 & 6.13 & 6.0 & $\mathrm{n} / \mathrm{a}$ & 0 & 7.50 & 6.0 & $\mathrm{n} / \mathrm{a}$ \\
1 & 1 & 5.36 & 5.8 & $\mathrm{n} / \mathrm{a}$ & 1 & 5.72 & 6.0 & $\mathrm{n} / \mathrm{a}$ \\
10 & 1 & 4.07 & 17.0 & $\mathrm{n} / \mathrm{a}$ & 2 & 4.00 & 20.0 & $\mathrm{n} / \mathrm{a}$ \\
20 & 1 & 3.62 & 52.6 & 36.5 & 3 & 3.78 & 56.8 & 38 \\
1 & 10 & 3.95 & 3.90 & $\mathrm{n} / \mathrm{a}$ & 2 & 4.20 & 3.6 & $\mathrm{n} / \mathrm{a}$ \\
1 & 20 & 3.52 & 3.45 & $\mathrm{n} / \mathrm{a}$ & 3 & 3.79 & 3.2 & $\mathrm{n} / \mathrm{a}$
\end{tabular}

TABLE II

Summary of the ReSults From Full-WaVe ANALYSIS With DIFFERENT PAIRS OF $L_{1}$ AND $L_{2} . h=10 \mathrm{~mm}$, line $l=20 \mathrm{~mm}$, line $\_w=1 \mathrm{~mm} p_{1}=0.3 \mathrm{~mm}, p_{2}=0.5 \operatorname{mmAND} \varepsilon_{r}=1$

\begin{tabular}{cc|ccc|c}
$L_{1}$ & $L_{2}$ & $f_{0}$ & $Z_{r}$ & $\begin{array}{c}\text { BW } \\
(\%)\end{array}$ & line_l $l \times l_{-}{ }^{2}+w \times h$ \\
\hline 0 & 0 & 4.36 & 42.66 & 8.20 & $0.291 \lambda \times 0.014 \lambda \times 0.145 \lambda$ \\
14 & 10 & 2.77 & 54.57 & 3.33 & $0.185 \lambda \times 0.009 \lambda \times 0.092 \lambda$ \\
30 & 30 & 1.93 & 51.14 & 2.42 & $0.129 \lambda \times 0.006 \lambda \times 0.064 \lambda$ \\
65 & 100 & 1.23 & 48.35 & 2.09 & $0.082 \lambda \times 0.004 \lambda \times 0.041 \lambda$ \\
110 & 220 & 0.91 & 54.30 & 2.16 & $0.061 \lambda \times 0.003 \lambda \times 0.030 \lambda$ \\
190 & 400 & 0.74 & 54.60 & 2.20 & $0.049 \lambda \times 0.002 \lambda \times 0.025 \lambda$
\end{tabular}

possible values of $M$ and selected the $M$ value to match the results from the full-wave analysis to those from the circuit analysis.

Resonant frequencies $\left(f_{0}\right)$, input impedance at $f_{0}\left(Z_{r}\right)$, and input impedance bandwidths (BWs) (BW, if it is available) from the circuit analysis agree well with those from full-wave analysis for different values of $L_{1}$ and $L_{2}$ except when $L_{1}=L_{2}=$ 0 . As the value of $L_{1}$ increases from $1 \mathrm{nH}$ to $20 \mathrm{nH}, f_{0}$ decreases and $Z_{r}$ increases. On the other hand, as the value of $L_{2}$ increases, $f_{0}$ and $Z_{r}$ decrease simultaneously. Hence, $Z_{r}$ can be easily matched to $50 \Omega$, and the antenna size can be reduced by properly choosing the values of $L_{1}$ and $L_{2}$. Note that when $L_{1}$ is $20 \mathrm{nH}$ and $L_{2}$ is $1 \mathrm{nH}$, the input impedance is matched to 50 $\Omega$ and the input impedance BW is $36.45 \mathrm{MHz}$.

\section{Full-WaVe ANALYsis}

To demonstrate the circuit characteristics in the previous section, we designed several antennas for different $L_{1}$ and $L_{2}$ combinations which guarantee good input impedance matching. We summarize $f_{0}, Z_{r}$, BW, and the electric size in Table II. The parameters are set as $h=10 \mathrm{~mm}$, line_l $=20 \mathrm{~mm}$, line_w $=1$ $\mathrm{mm}, p_{1}=0.3 \mathrm{~mm}, p_{2}=0.5 \mathrm{~mm}$, and $\varepsilon_{r}=1$.

When $L_{1}=L_{2}=0, f_{0}$ is $4.36 \mathrm{GHz}$ and BW is $8.2 \%$. When $L_{1}=14 \mathrm{nH}$ and $L_{2}=10 \mathrm{nH}, f_{0}$ is $2.77 \mathrm{GHz}$ and BW is $3.33 \%$, which is lower than when $L_{1}=L_{2}=0$. As the values of $L_{1}$ and $L_{2}$ increase, $f_{0}$ decreases with good impedance matching. This means that the operating frequency of the proposed antenna can be controlled by $L_{1}$ and $L_{2}$ without changing antenna dimensions. Note that even though $f_{0}$ decreases (the antenna is miniaturized), the fractional bandwidth is kept almost constant from 


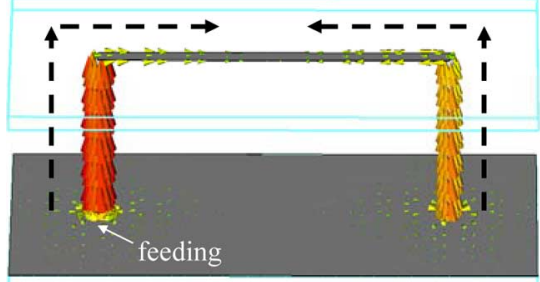

(a)

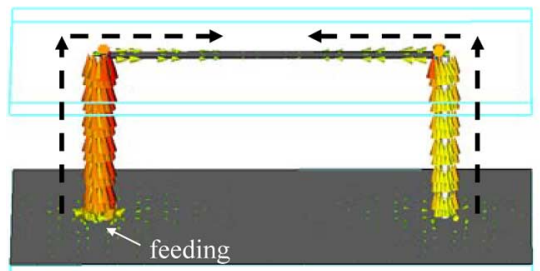

(b)

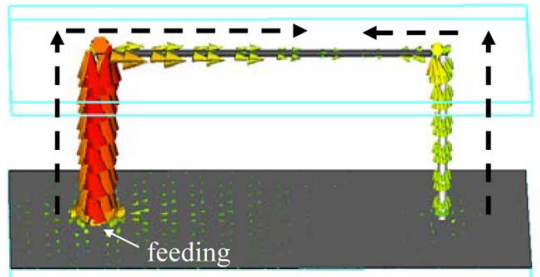

(c)

Fig. 4. Surface current distribution for different inductor pairs. (a) $L_{1}=L_{2}=$ $0 \mathrm{nH}$ at $4.36 \mathrm{GHz}$. (b) $L_{1}=L_{2}=30 \mathrm{nH}$ at $1.93 \mathrm{GHz}$. (c) $L_{1}=110 \mathrm{nH}$, $L_{2}=220 \mathrm{nH}$ at $0.91 \mathrm{GHz}$.

the third to the sixth row in Table II. This characteristic is very desirable. As the operating frequency decreases by integrating high inductance inductors, a distributed shunt capacitor between the upper horizontal wire and the bottom ground plane is also increased in the fixed physical dimension. The increased capacitance compensates for the increased inductance of the lumped inductors and for the stored magnetic energy. Therefore, the bandwidth of this antenna can be kept constant. This characteristic is a key advantage of the proposed antenna.

To verify the current directions of Fig. 1, we present simulated current distributions at $f_{0}$ for different inductors pairs in Fig. 4. The current distributions are almost kept unchanged, although higher inductance inductors are integrated. A current null position on the upper line slightly shifts in Fig. 4(c), but the amount of the shift is not much compared to the decrease in operating frequency.

\section{FABRICATION AND MEASUREMENT RESUlts}

To validate the simulation results, we fabricated several proposed antennas with different combinations of $L_{1}$ and $L_{2}$. Fig. 5 shows the fabricated antennas with and without inductors. The design parameters are line_l $=28 \mathrm{~mm}$, line_ $w=3 \mathrm{~mm}, h=$ $11.2 \mathrm{~mm}$, and $p_{1}=p_{2}=0.9 \mathrm{~mm}$. We use an FR4 substrate of 0.8 -mm thickness, and LQW18A series Murata coil inductors.

Fig. 6 shows the measured and simulated return losses of the proposed antennas with three different inductor pairs $\left(L_{1}=\right.$ $\left.0 \mathrm{nH}, L_{2}=0 \mathrm{nH}\right),\left(L_{1}=10 \mathrm{nH}, L_{2}=5.6 \mathrm{nH}\right)$, and $\left(L_{1}=\right.$ $33 \mathrm{nH}), L_{2}=33 \mathrm{nH}$ ). This figure demonstrates that the proposed antenna's operating frequency can be controlled using

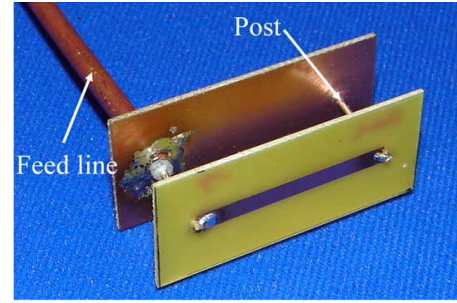

(a)

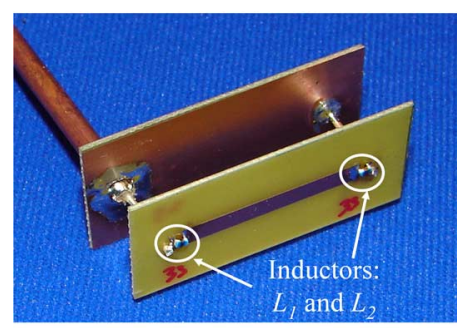

(b)

Fig. 5. Fabricated proposed antennas. (a) Without inductor. (b) With inductor.

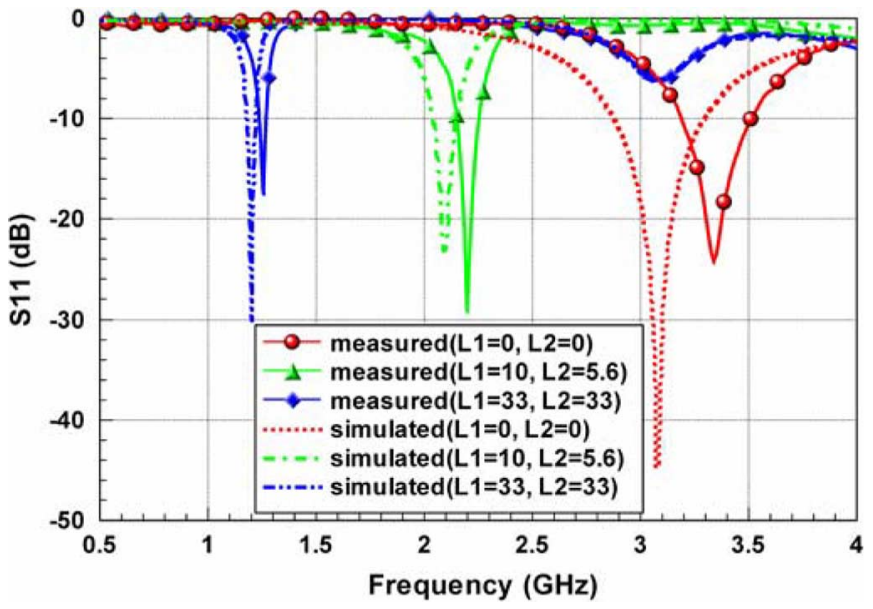

Fig. 6. Measured return loss with different inductor pairs.

simple passive devices. As the inductor pairs increase from (10 $\mathrm{nH}, 5.6 \mathrm{nH})$ to $(33 \mathrm{nH}, 33 \mathrm{nH})$, the measured center operating frequencies decrease from 2.19 to $1.26 \mathrm{GHz}$, which is very similar to the changes in the simulated ones (i.e., 2.07 and $1.2 \mathrm{GHz}$ ). When $L_{1}=10 \mathrm{nH}$ and $L_{2}=5.6 \mathrm{nH}$, the measured input impedance bandwidth is $102 \mathrm{MHz}(4.7 \%)$ and the simulated bandwidth is $101 \mathrm{MHz}(4.9 \%)$. When $L_{1}=33 \mathrm{nH}$ and $L_{2}=$ $33 \mathrm{nH}$, the measured impedance bandwidth is $28 \mathrm{MHz}(2.2 \%)$ and the simulated bandwidth is $33 \mathrm{MHz}(2.8 \%)$. The minor differences between the measured and simulated results might be due to fabrication error since the fabrications are not optimized. Note that the electrical dimension line $l \times$ line $w$ $w h$ of the fabricated antenna with $L_{1}=33 \mathrm{nH}$ and $L_{2}=33 \mathrm{nH}$, is only $0.118 \lambda \times 0.013 \lambda \times 0.047 \lambda$. If a combination of higher inductance inductors is used, the size can be further decreased without degrading the fractional bandwidth.

The radiation patterns of the fabricated antenna with $L_{1}=$ $10 \mathrm{nH}$ and $L_{2}=5.6 \mathrm{nH}$ at $2.21 \mathrm{GHz}$ were measured using $5^{\circ}$ resolution in an anechoic chamber, and the measured and simulated patterns at the $y-z$ plane are presented in Fig. 7. The co-pol 


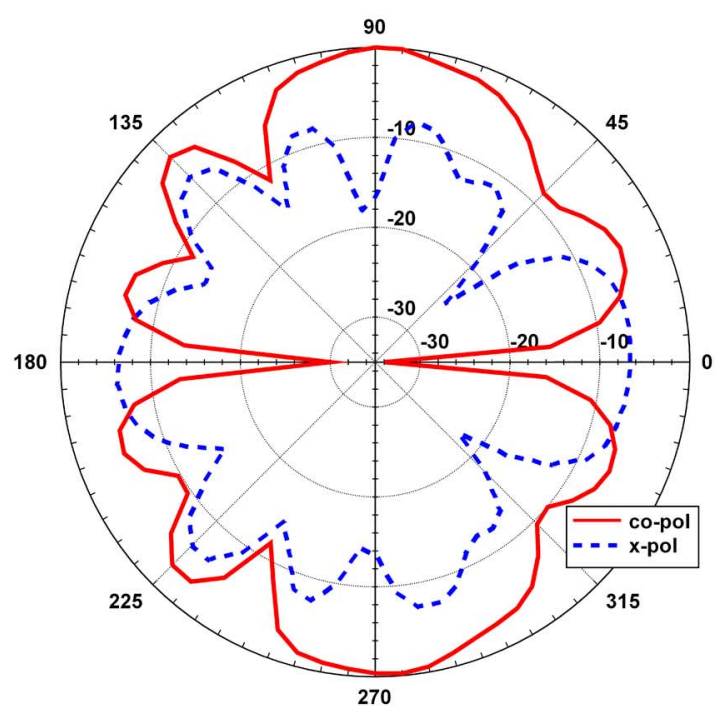

(a)

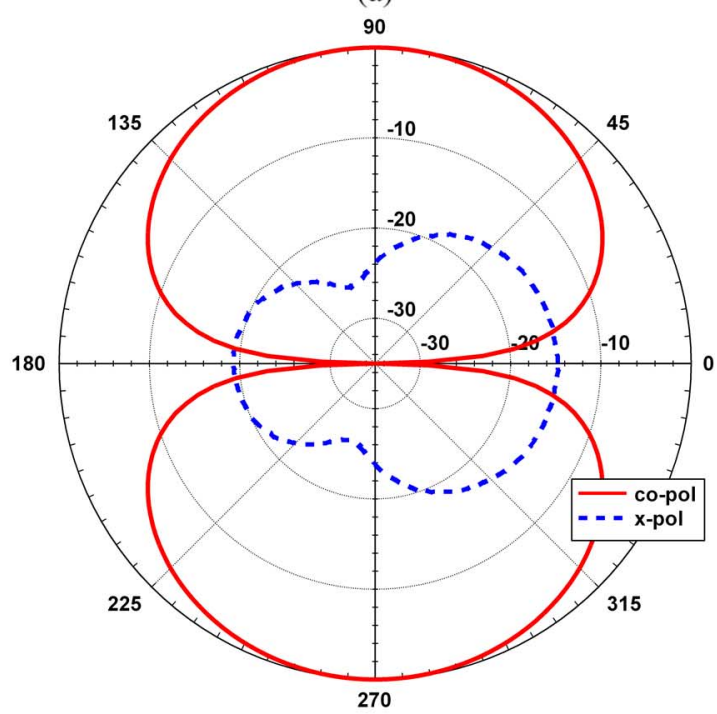

(b)

Fig. 7. Radiation patterns at $2.21 \mathrm{MHz}$ (y-z plane). (a) Measured. (b) Simulated. ( $L_{1}=10 \mathrm{nH}, L_{2}=5.6 \mathrm{nH}$, co-pol: $E_{\theta}$, x-pol: $\left.E_{\Phi}\right)$. and the x-pol in the figure are $E_{\theta}$ and $E_{\Phi}$, respectively. Nulls in the co-pol occur at $0^{\circ}$ and $180^{\circ}$. This radiation characteristic occurs because the dominant radiation elements are two vertical posts. The component of $E_{\Phi}$ is measured as relatively large, because the small ground plane causes radiation on the coaxial feeding line of the fabricated antenna. The measured radiation efficiency is $33.3 \%$.

\section{CONCLUSION}

In this letter, we have proposed a new technique for miniaturization loop antennas by integrating two inductors. The results show that the resonant frequency decreases and the input resistance increases as $L_{1}$ is increased, but that resonant frequency and input resistance decrease as $L_{2}$ is increased. These characteristics allow the antenna to have the tunable operating frequency and make the antenna electromagnetically small. Moreover, the key advantage of this antenna is its constant fraction input impedance bandwidth across its entire tunable frequency range.

The measured results are compared to the simulations, and show good agreement with the simulated results. One of the fabricated antennas only has a $0.118 \lambda \times 0.013 \lambda \times 0.047 \lambda$ electrical size at $1.2 \mathrm{GHz}$.

\section{REFERENCES}

[1] R. Porath, "Theory of miniaturized shorting-post microstrip antennas," IEEE Trans. Antennas Propag., vol. 48, no. 1, pp. 41-47, Jan. 2000.

[2] J. Anguera, L. Boada, C. Puente, and J. Soler, "Stacked H-shaped microstrip patch antenna," IEEE Trans. Antennas Propag., vol. 52, no. 4, pp. 983-993, Apr. 2004.

[3] D. M. Pozar and A. Adrian, "Effect of microstrip antenna substrate thickness and permittivity," IEEE Trans. Antennas Propag., vol. 37, no. 6, pp. 677-682, Jun. 1989.

[4] J. H. Lu and K. L. Wong, "Slot-loaded meandered rectangular microstrip antenna with compact dual-frequency operation," Electron. Lett., vol. 34, pp. 1048-1050, May 1998.

[5] J. H. Jung and I. Park, "Electromagnetically coupled small broadband monopole antenna," IEEE Antennas Wireless Propag. Lett, vol. 2, no. 1, pp. 349-351, 2003.

[6] J. A. Dobbins and R. L. Rogers, "Folded conical helix antenna," IEEE Trans. Antennas Propag., vol. 49, no. 12, pp. 1777-1781, Dec. 2001. 